\title{
SenStick: Comprehensive Sensing Platform with an Ultra Tiny All-In-One Sensor Board for IoT Research
}

\author{
Yugo Nakamura, Yutaka Arakawa, Takuya Kanehira, \\ Masashi Fujiwara, and Keiichi Yasumoto \\ Graduate School of Information Science, Nara Institute of Science and Technology, 8916-5 Takayama-cho, Ikoma, Nara 630-0192, Japan \\ Correspondence should be addressed to Yugo Nakamura; nakamura.yugo.ns0@is.naist.jp
}

Received 13 June 2017; Revised 31 August 2017; Accepted 20 September 2017; Published 26 October 2017

Academic Editor: Alberto J. Palma

Copyright (c) 2017 Yugo Nakamura et al. This is an open access article distributed under the Creative Commons Attribution License, which permits unrestricted use, distribution, and reproduction in any medium, provided the original work is properly cited.

\begin{abstract}
We propose a comprehensive sensing platform called SenStick, which is composed of hardware (ultra tiny all-in-one sensor board), software (iOS, Android, and PC), and 3D case data. The platform aims to allow all the researchers to start IoT research, such as activity recognition and context estimation, easily and efficiently. The most important contribution is the hardware that we have designed. Various sensors often used for research are embedded in an ultra tiny board with the size of $50 \mathrm{~mm}(W) \times 10 \mathrm{~mm}(H) \times$ $5 \mathrm{~mm}(D)$ and weight around $3 \mathrm{~g}$ including a battery. Concretely, the following sensors are embedded on this board: acceleration, gyro, magnetic, light, UV, temperature, humidity, and pressure. In addition, this board has BLE (Bluetooth low energy) connectivity and capability of a rechargeable battery. By using $110 \mathrm{mAh}$ battery, it can run more than 15 hours. The most different point from other similar boards is that our board has a large flash memory for logging all the data without a smartphone. By using SenStick, all the users can collect various data easily and focus on IoT data analytics. In this paper, we introduce SenStick platform and some case studies. Through the user study, we confirmed the usefulness of our proposed platform.
\end{abstract}

\section{Introduction}

The rapid growth of Internet of Things (IoT) has made it possible to sense many types of information from the real world. In the research area of human activity recognition, IoT devices equipped with various sensors have been widely used as a tool for sensing the activities. There are three approaches of activity recognition studies in terms of sensor deployment.

The first approach deploys sensors into the environment like a smart home. As typical sensors, camera [1], sound [2], and power consumption [3] have been used for monitoring dweller's activities.

In the second approach, sensors are attached to the human. The smartphone has been widely used $[4,5]$ as a sensing tool in this approach because it has many sensors (an acceleration sensor, gyro sensor, magnetic sensor, etc.) as well as a processor, a large data storage, and wireless network. Nowadays, instead of the smartphone, wearable devices such as a smartwatch are used [6]. JINS MEME [7] is a smart eyewear having the electrooculography (EOG) electrodes in the bridge of the glasses and the nose pads. It tries to measure the movement of eyes for recognizing the internal contexts such as drowsiness and tiredness. Also, we have proposed Waiston Belt [8] that can measure the abdominal circumference and posture.

The third approach is a new paradigm where sensors are embedded in the various things surrounding us. Kurahashi et al. [9] have installed an acceleration sensor into a toilet paper holder for recognizing the person. HAPIfork [10] has embedded an acceleration sensor into a fork for monitoring eating activities. We have also added an acceleration sensor on a faucet of water or a remote control for sensing various activities of the dweller. We think that the spread of IoT makes more things have a sensor and network connectivity. In the following sections, we define the words "sensorize (verb)" and "sensorization (noun)" as the procedure to add the sensor and wireless network to the nonelectronic personal belongings.

However, sensorization of tiny things is difficult and costly for the researcher. Nowadays, various rapid prototyping platforms such as Arduino, Mbed, and Raspberry Pi have already spread by the maker movement. They are cheap and useful, but there are some problems for sensorizing tiny 


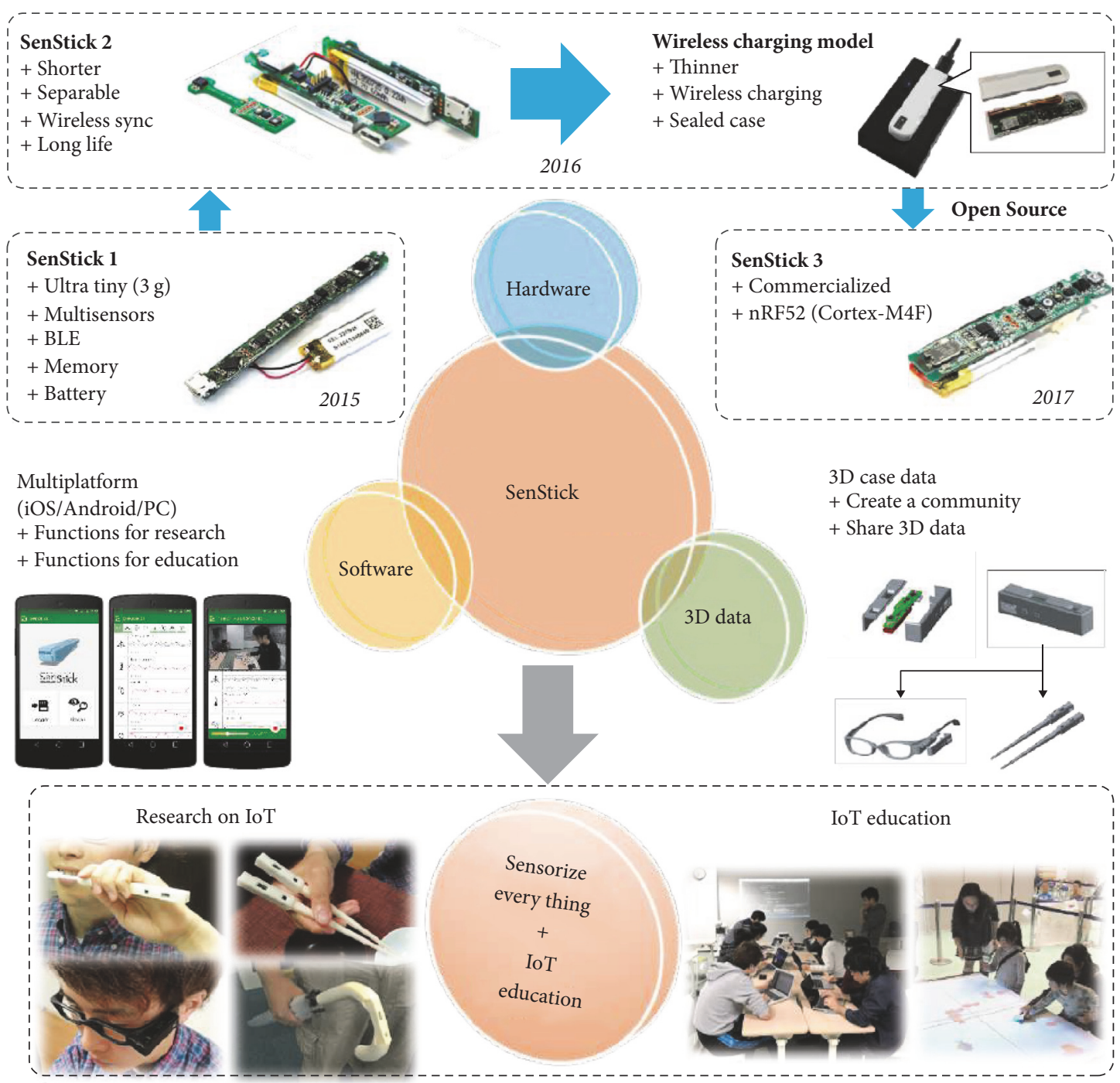

FIGURE 1: SenStick platform including hardware, software, and community.

things mentioned as follows. The size of the board is relatively large. In addition, the final deliverables usually become larger because the baseboard requires various additional functions such as a charging circuit, clock, and storage and those are connected via the relatively large connector. As a result, it is actually difficult to develop "small" sensorized things that can be used in the actual environment. Another problem is software for controlling the deliverable from a smartphone. It is not easy to develop a sophisticated mobile application for each deliverable, respectively. Since the essence of IoT is data analysis, sensorization of everything should be simplified and solution for collecting data smoothly is required.

Based on above-mentioned background, we started developing a platform, called SenStick [11], for sensorizing various things more easily in 2014. Our proposed SenStick is a comprehensive platform including the hardware, software, $3 \mathrm{D}$ case data, and community as shown in Figure 1. SenStick aims to allow researchers to sensorize everything and also educators to teach IoT-related techniques such as data analysis. The size of the first SenStick board released in 2015 (SenStick 1) is $75 \mathrm{~mm}(W) \times 10 \mathrm{~mm}(H) \times 5 \mathrm{~mm}$ $(D)$ and its weight is around $3 \mathrm{~g}$ including a battery. On this tiny board, 8 sensors (acceleration, gyro, magnetic, light, UV, temperature, humidity, and pressure), flash memory, BLE, battery, and charging circuit are densely embedded.

The second version of the hardware (called SenStick 2), released in 2016 [12], became shorter, $50 \mathrm{~mm}(W) \times 10 \mathrm{~mm}$ $(H) \times 5 \mathrm{~mm}(D)$, by dividing the board into two boards and connecting them vertically. By updating the firmware, the battery life of SenStick 2 reached 15 hours by 60 mAh battery. Also, wireless data synchronization function and Device Firmware Update (DFU) over BLE have been implemented. SenStick 2 has a derivative version (wireless charging model). This version has a different battery type and charging circuit for enabling wireless charging.

In 2017, the third version of the hardware (called SenStick 3) was sold from a company (http://senstick.com/). Almost all the configurations of SenStick 3 are the same as SenStick 
2 but the board is unified into one board again like SenStick 1. The main change is the upgrade of BLE chip from nRF51 to nRF52. Since the processing power is increased, we can add some calculation process on the board.

In the software part, support application is developed for mobile devices (iOS and Android) and desktop PC (Linux, macOS, and Windows). Each application can monitor and record sensing data synchronously and can configure the parameters of each sensor. The Android version can simultaneously record a ground truth video and sensing data. The PC version allows a user to connect multiple SenSticks simultaneously and also provides a function to use NodeRED which provides a simple programming interface.

In 3D case part, we designed the data of basic 3D case of SenStick. It is possible to easily design the 3D case for various things by using our base 3D case data.

The remaining part of the paper is organized as follows. We first introduce various existing products and compare them with SenStick in Section 2. Next, we explain the details of our proposed platform SenStick in Section 3. In Section 4, we introduce some case studies utilizing SenStick and some survey results answered by students who actually used SenStick platform. Finally, we conclude the paper in Section 5.

\section{Related Work}

We summarize competitive sensors in the market in Table 1.

SensorTag [13] of Texas Instruments is the most competitive sensor board similar to SenStick. The sensors embedded on SensorTag are almost the same as SenStick except for UV sensor. However, SensorTag does not have stand-alone data recording function and a flash memory, because this sensor is designed on the premise that sensing data are always stored on the smartphone connected by BLE. Since the main target of SensorTag is environmental sensing, the sensing frequency of motion sensors is limited up to $1 \mathrm{~Hz}$ and a rechargeable battery is adopted. Therefore, it is not suitable for activity sensing of IoT research. In addition, the board shape, size, and weight are completely different. SenStick is much smaller and slimmer.

IoT Smart Module [14] is a small sensor board equipped with several sensors like SensorTag. Support applications provide functions to cooperate with IBM Bluemix, so it is possible to smoothly perform tasks from sensing of data to cloud analysis. However, support applications only work on Android. Similar to SensorTag of $\mathrm{Ti}$, it adopts nonrechargeable coin battery. Although it can set higher sensing frequency, a user must change the coin battery at short intervals. Also, logically, it cannot transmit all the sensing data in case of higher sensing frequency, because the transmission capacity of BLE is low. Therefore, it is not suitable for research that requires precise data.

TSND121 [15] of ATR-Promotions is another competitive sensor because it was used in some academic research. It has 9-axis motion sensors and ambient pressure sensor and adopts Classic Bluetooth 2.0 for transmitting data. Because it only focuses on monitoring activities of a human and a robot, the size of the sensor is relatively large but at most 7 sensors can be simultaneously connected to a control PC.
Since it always requires a PC for recording sensed data, it is not suitable for sensing our daily life out of the lab.

WAX9 [16] of Axivity used in UK Biobank [17] was a streaming inertial measurement unit (IMU) which has a large flash memory for logging. The sensor combines a MEMS accelerometer, gyro, and magnetometer with a Bluetooth low energy (BLE) compatible radio. Additionally, WAX9 also features a barometric pressure sensor and temperature sensor. However, it does not have some environmental sensors such as humidity, light, and UV sensor and always only distributes the Windows-compatible software for data collection and visualization. It has already been discontinued.

Based on the features of other competing sensors, we summarize the requirements for SenStick platform.

(1) Hardware Requirements. The SenStick platform aims to sense tiny activities that cannot be sensed by existing smartphones and wearable devices. Therefore, essential functions must be embedded in a small sensor board, and each sensor must collect data in high sampling rate. Since BLE communication dose not guarantee reliable data communication, it is necessary to be able to record in standalone without recording devices such as a smartphone. In addition, it is required that the SenStick must have rechargeable battery system because a coin battery is not suitable for frequent use.

(2) Software Requirements. The SenStick platform aims to simplify the data collection and analysis from sensorized things. Therefore, support software should be multiplatform. It should be compatible with the various operating systems. Support software requires not only basic function such as data recording but also additional functions such as simultaneous recording of sensing data from multiple SenSticks and simple programming interface for data processing.

(3) 3D Case Requirements. The SenStick platform aims to promote the sensorization of everything. For this purpose, it is desirable to provide a 3D case of SenStick that can be attached to various belongings. Further, 3D cases created by someone should be shared with other users through our website.

\section{Comprehensive Sensing Platform for IoT Research: SenStick}

Our proposed platform called SenStick consists of 3 components: hardware, software, and $3 \mathrm{D}$ case. In the following subsections, we explain the details of these components. This platform allows a user to sensorize everything easily and efficiently. We believe that it supports the rapid prototyping by researchers and is useful for IoT education (a video illustrating SenStick's hardware, software, and 3D case data is provided in Supplementary Material available online at https://doi.org/10.1155/2017/6308302).

3.1. Hardware. As we explained in Section 1, we have updated the hardware three times from 2015. The explanation in the following part is based on SenStick 2 developed in 2016. The size of the sensor board is $55 \mathrm{~mm}(W) \times 10 \mathrm{~mm}(H)$ 


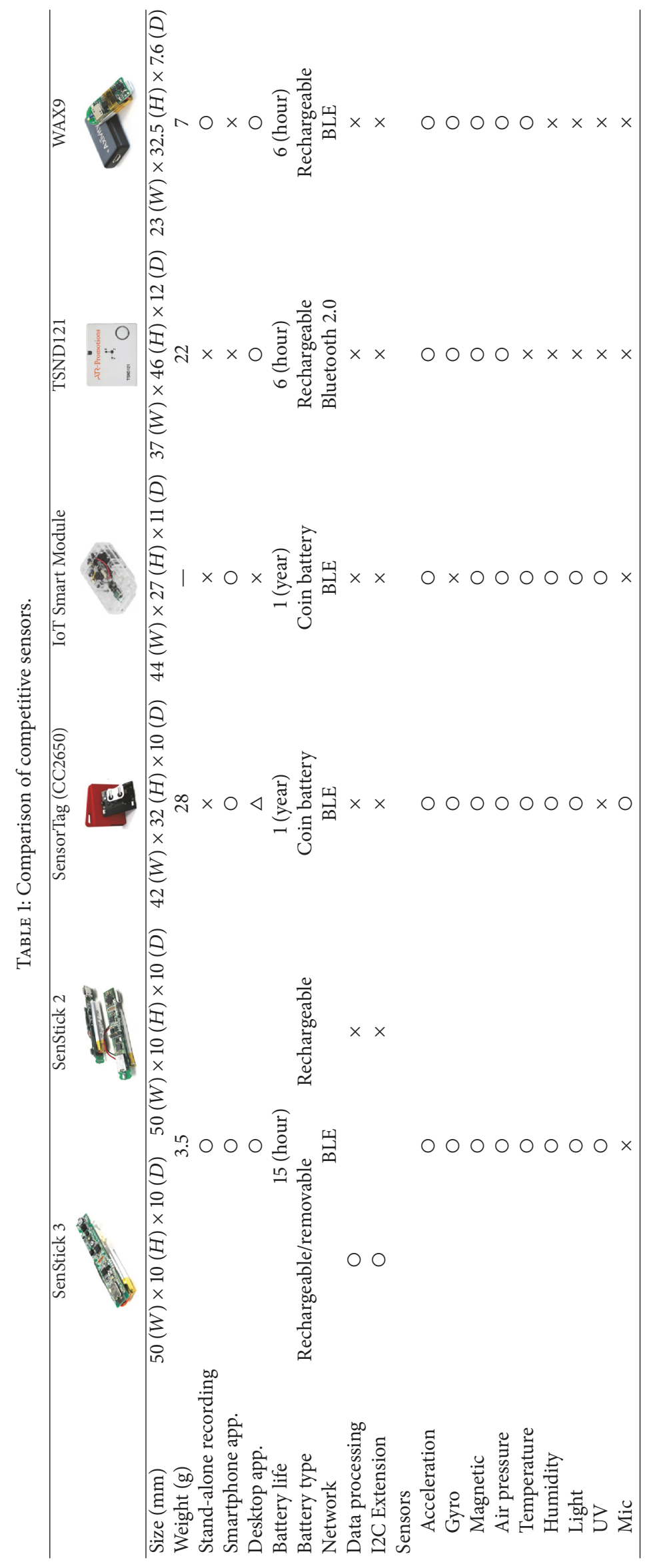




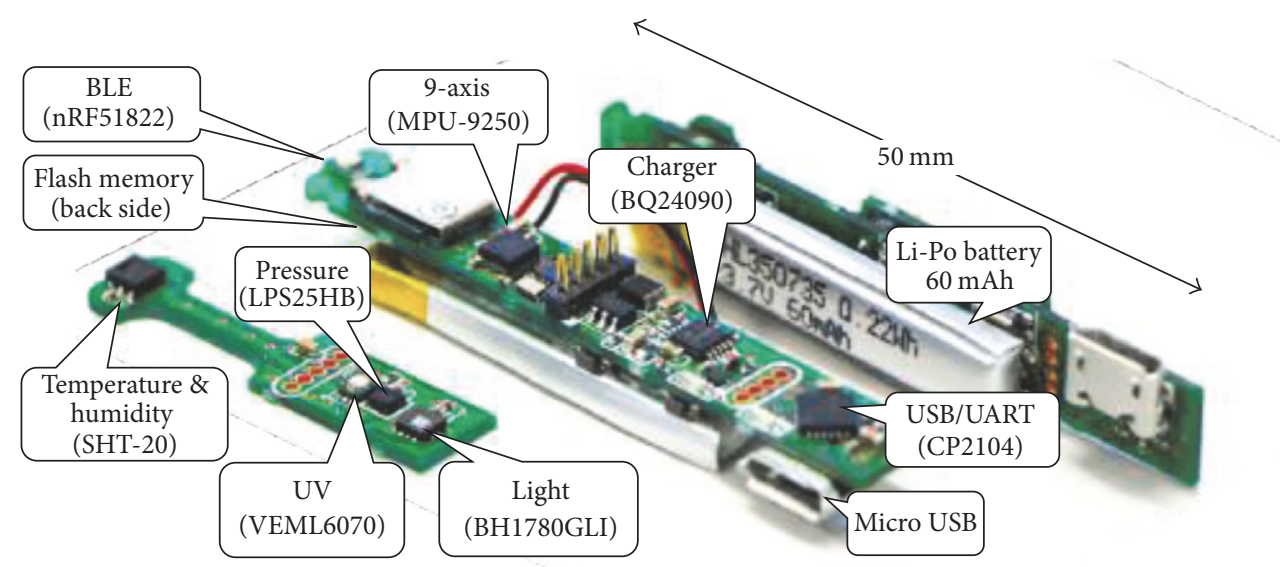

Figure 2: Hardware of SenStick 2 (8 sensors, BLE, flash memory, etc.).

TABLE 2: Sensors embedded in SenStick 2/3.

\begin{tabular}{lcc}
\hline Type of sensor & Model number & Power consumption \\
\hline 9-Axis & MPU-9250 & $280 \mu \mathrm{A} \sim 3.7 \mathrm{~mA}$ \\
Pressure & LPS25HBTR & $4 \mu \mathrm{A} \sim 25 \mu \mathrm{A}$ \\
Temperature/humidity & SHT20 & $270 \mu \mathrm{A} \sim 330 \mu \mathrm{A}$ \\
Illuminance & BH1780GLI-E2 & $120 \mu \mathrm{A} \sim 200 \mu \mathrm{A}$ \\
Ultraviolet (UV) & VEML6070 & $100 \mu \mathrm{A} \sim 250 \mu \mathrm{A}$ \\
\hline
\end{tabular}

$\times 5 \mathrm{~mm}(D)$, and its weight is around $3(\mathrm{~g})$ including the battery. On this tiny board, eight sensors (acceleration, gyro, magnetic, light, UV, temperature, humidity, and pressure), flash memory (32 Mbytes), BLE, battery, and charging circuit are densely embedded as shown in Figure 2. The model number and power consumption of the sensors embedded in SenStick are listed in Table 2. All the sensors are popular chips used worldwide, and their performances are ensured by each manufacturer.

The novelty of our hardware is the design of the sensor board composed of the elaborated combination to satisfy the requirements presented in Section 2. This contribution breaks down into the following aspects.

(1) Combination of BLE and Flash Memory. Almost all the BLE-based devices equipped no large flash memory to record sensing data, because these devices are designed on the premise that sensing data are always recorded on smartphones connected via BLE. However, the transmission speed of BLE is not enough for sending all the sensing data of multiple sensors with the high sampling frequency. As a result, some data will be dropped in the transmission. Since the design of existing BLE-based devices is not appropriate for research purpose, we designed a new BLE-based sensing board with a large flash memory, which allows users to record all the sensing data precisely. Also, it means that it can work without holding a smartphone. This ability is useful for sensing the motion of animals that cannot have a smartphone.
(2) Selection of Powerful and Energy-Saving SoC. We selected Nordic's nRF52832 SoC as SenStick's microcontroller. Because the nRF52832 SoC is built around a 32bit ARM Cortex-M4F CPU with $512 \mathrm{kB}+64 \mathrm{kB}$ RAM, it is extremely powerful. Moreover, the embedded $2.4 \mathrm{GHz}$ transceiver supports Bluetooth low energy and has extremely low power consumption and it is the world's smallest class module. Each sensor is connected via two I2C buses, independently processing high-speed sensor (acceleration, gyro, and magnetic) and low-speed sensor (light, UV, temperature, humidity, and pressure), taking into account the difference in bus occupancy time. This makes it possible to realize high sampling with the motion sensors.

(3) Application-Friendly Battery Type and Shape. Since SenStick is designed to be mounted on objects such as chopsticks, toothbrushes, and glasses, it is desirable that the shape is thin and compact. However, sensors such as SensorTag equipped with readily available coin batteries are inappropriate in shape because the footprint is square. Also, in the research, nonrechargeable coin batteries are costly and troublesome. For those reasons, we selected a thin and compact lithium polymer battery on SenStick. This type of battery was harder to obtain than expected. Therefore, the procurement of battery has become the bottleneck of development.

SenStick's firmware is newly designed and developed by considering aforementioned requirements. Generic Attribute (GATT) profile of SenStick provided by firmware is shown in Figure 3. The GATT server in SenStick provides three services (SenStick Control Service, Metadata Read Service, and Sensor Service). The SenStick Control Service provides operation instructions such as starting and stopping sensing and logging. The metadata reading service provides the function of reading metainformation of log data. The Sensor Service provides functions to specify the sensing and logging operation of each sensor (0: acceleration, 1: gyro, 2: magnetic, 3: light, 4: UV, 5: temperature/humidity, 6: pressure). Also, it provides real-time sensing data reading function and log data reading function. 


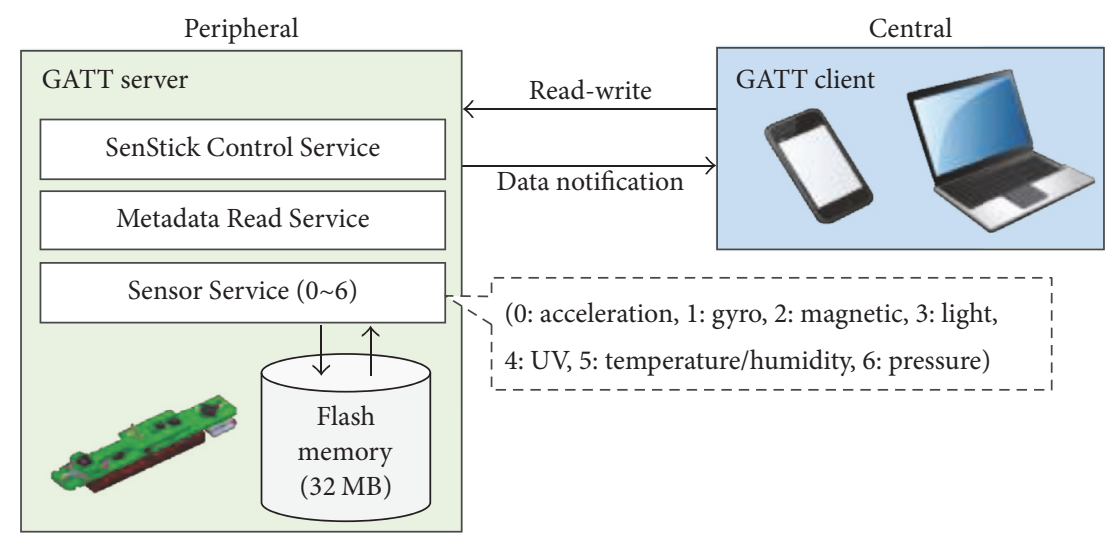

FIGURE 3: Generic Attribute (GATT) profile of SenStick.

TABLE 3: BLE communication specification.

\begin{tabular}{lc}
\hline Type of content & Spec. \\
\hline Advertising packet & Complete UUID, flag \\
Scan response & Local name (SenStick) \\
Advertising packet interval & $100 \mathrm{~ms}(30 \mathrm{~s}) \rightarrow 1000 \mathrm{~ms}(150 \mathrm{~s}) \rightarrow$ sleep \\
Connection interval & max: $80 \mathrm{~ms} / \mathrm{min}: 20 \mathrm{~ms}$ \\
Supervision timeout & $4000 \mathrm{~ms}$ \\
Slave latency & 0 \\
\hline
\end{tabular}

Basically, all the sensing data will be notified to a smartphone in real time up to a transmission capacity of BLE. If the amount of sensing data exceeds the transmission capacity, a part of sensing data will be dropped. Therefore, the realtime sensing data reading function is used for monitoring the status or for an interactive application that does not require precise data. For precise data acquisition, the log data reading function, which guarantees the data reading order, is used. The communication specifications of BLE are described in Table 3.

As shown in Table 4, the fixed capacities of a flash memory are allocated to each sensor. The number of samples indicates the total number of samples that can be recorded by the allocated capacities.

SenStick stops logging when the number of samples of one sensor exceeds the storage capacity allocated for it. The maximum recording time of acceleration, gyroscope, and magnetic sensor is 4 hours 40 minutes at sampling interval of 10 milliseconds (sampling frequency: $100 \mathrm{~Hz}$ ) and 14 hours 10 minutes at sampling period of 30 milliseconds (sampling frequency: $33 \mathrm{~Hz}$ ). The maximum recording time of other sensors is 9 hours 26 minutes at sampling period of 200 milliseconds (sampling frequency: $5 \mathrm{~Hz}$ ).

3.2. Software. We provide mobile applications for iOS and Android and a library for node.js platform. Common functions of them are operating function, parameter setting function, and real-time data view function. An additional
TABLE 4: Allocated storage capacity per sensor.

\begin{tabular}{lcc}
\hline & $\begin{array}{c}\text { Amount of allocated } \\
\text { storage capacity }\end{array}$ & Samples \\
\hline Acceleration & 10.2 Mbytes & $1.7 \mathrm{M}$ samples \\
Gyro & 10.2 Mbytes & $1.7 \mathrm{M}$ samples \\
Magnetic & 10.2 Mbytes & $1.7 \mathrm{M}$ samples \\
Illuminance & $340 \mathrm{~KB}$ & $170 \mathrm{~K}$ samples \\
UV (UV) & $340 \mathrm{~KB}$ & $170 \mathrm{~K}$ samples \\
Humidity & $170 \mathrm{~KB}$ & $170 \mathrm{~K}$ samples \\
Air temperature & $170 \mathrm{~KB}$ & $170 \mathrm{~K}$ samples \\
\hline
\end{tabular}

function of iOS application is a firmware update function. Those of Android application and node.js applications are ground truth video recording function and an ability to connect multiple SenSticks, respectively. Since all these software applications are shared on GitHub as an own source software, all the users can create their application based on their own purposes.

Communication Protocol. Here, we explain the communication protocol between SenStick and software. The explanation is based on "node-SenStick" which is our developed library for node.js. Figure 4 shows a protocol sequence between SenStick and the central terminal (node-SenStick on Mac).

(I) Discovery. First of all, the application needs to find the surrounding SenStick by using SenStick.discovery() method in our library. When SenStick.discovery() method finds a SenStick, a callback function with an instance of SenStick object containing the SenStick's UUID and LocalName as arguments is called.

(II) Connect. If the target SenStick is found by the discovery process, the application is going to establish a connection with it by calling SenStick.prototype.connectAndSetUp() method. After establishing the connection, this method acquires the information necessary for operation from the target SenStick. 


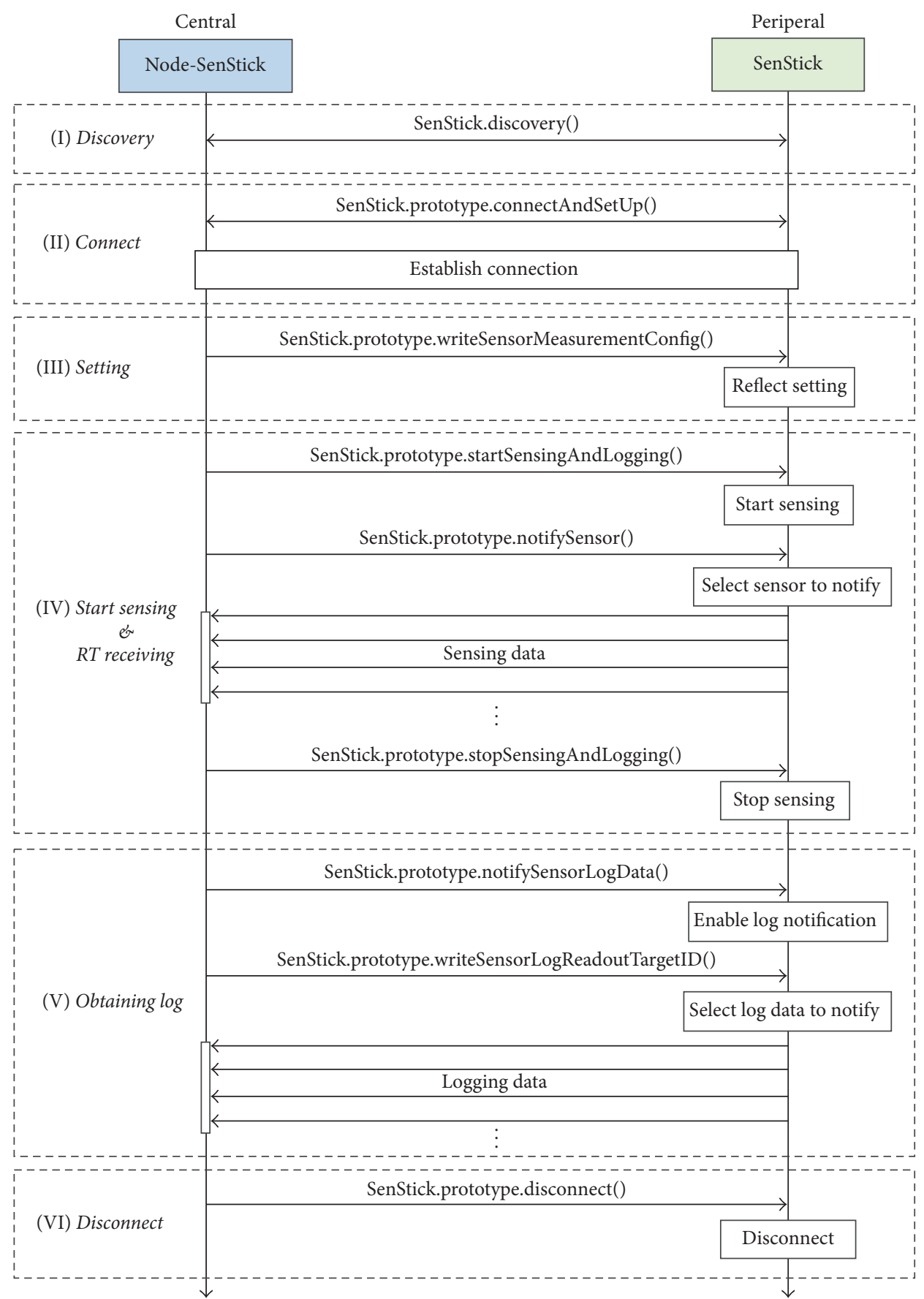

Figure 4: Communication sequence between SenStick and node-SenStick.

(III) Setting. After establishing the connection, the application sets three parameters (operation mode, sampling interval, and measurement range) for each sensor by using SenStick.prototype.writeSensorMeasurementConfig() method. The operation mode is a parameter that sets validation/invalidation of sensing and logging of each sensor. The sampling interval and measurement range are parameters of each sensor which will be changed by the sensing purpose and applications.
(IV) Start Sensing and Real-Time Data Receiving. When SenStick.prototype.startSensingAndLogging() method is called, SenStick starts sensing and logging. Only valid sensors' data are transmitted via BLE and also recorded into a flash memory. ID of each $\log$ is automatically assigned. During sensing, SenStick notifies sensing data in real time. To receive this notification, the application calls SenStick.prototype.notifySensor() method (Sensor represents each sensor name) and activates the notification for 


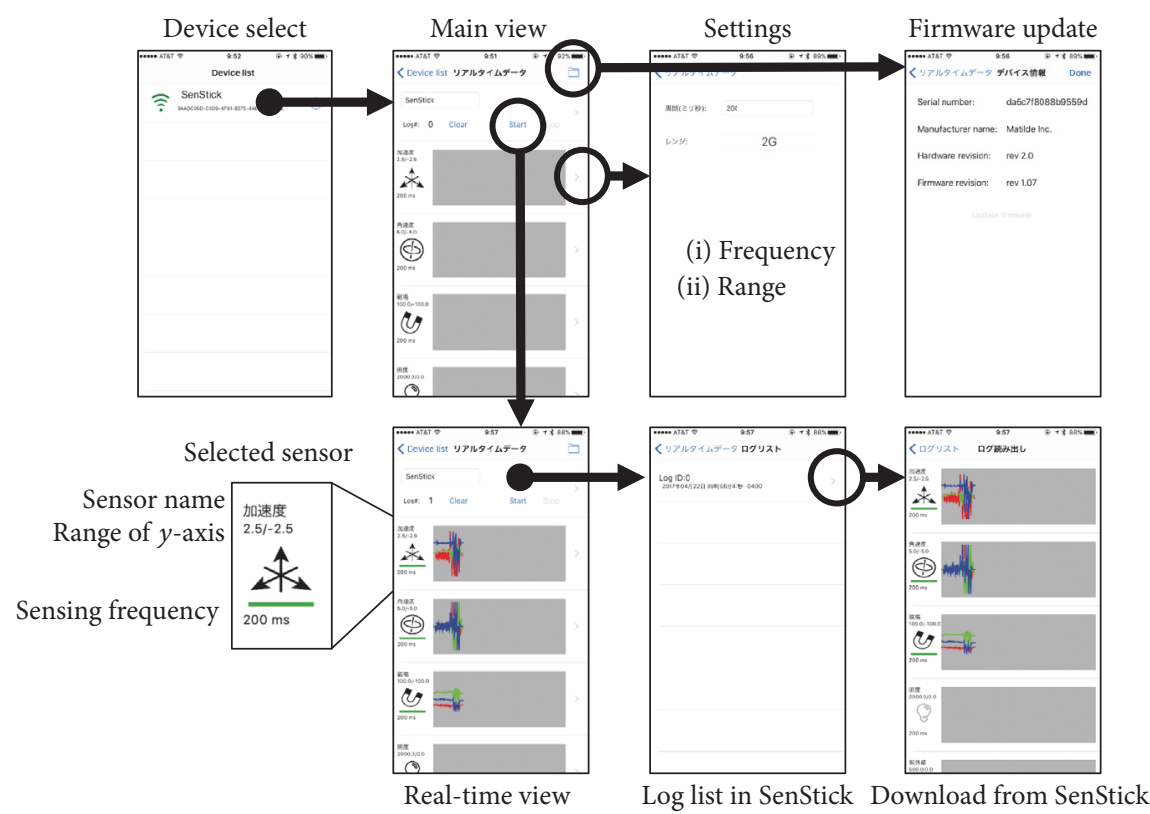

FIGURE 5: iOS application for SenStick.

the sensor. When a notification of sensing data is received, sensorChange event will be issued. If SenStick.prototype.stopSensingAndLogging() method is called, SenStick stops sensing and logging.

(V) Log Data Reading. To read the log data recorded in the flash memory to the application, the application calls SenStick.prototype.notifySensorLogData() method (Sensor represents each sensor name) and enables log data notification. If the application specifies a valid log ID by calling SenStick.prototype.writeSensorLogReadoutTargetID() method, SenStick starts informing the sensing data recorded in the log sequentially. To receive notification of log data, sensorLogDataReceived event will be issued. By receiving this notification by the application, it is possible to acquire the log data recorded in the memory.

(VI) Disconnect. After finishing the data acquisition, SenStick.prototype.disconnect() method will be called to release the connection of SenStick. And SenStick will begin advertising again.

User Interface. We explain the user interface of the application based on iOS version. Figure 5 shows a sophisticated mobile application for SenStick. As shown in Figure 5, the user selects target SenStick from devices list. Then, the application shows the main view. In the main view, the user can select sensors to be acquired. For immediate data monitoring, all the received data via BLE can be shown in the graph view in real time. The application can control all the settings of each sensor such as sample frequency and sensing range. And also it has firmware update function. Sensing data stored in the flash memory of SenStick is viewed from log list and it can be downloaded to the smartphone in CSV format. This function prevents data loss caused by BLE communication.

3.3. 3D Case Data. In order to make sensorized things, an attachment case for mounting the SenStick is required. We designed the basic 3D case of SenStick. By extending this basic case, users can design derivative cases for chopsticks, glasses, and so on. Actually, our laboratory has succeeded in designing cases for several things as shown in Figure 6. All of these cases data are shared on our community site. Each case is designed in a few minutes thanks to the basic case. For example, SenStick case for glasses is made by combining basic case of SenStick and open 3D data of glasses distributed by i Design Studio. In addition, due to the popularization of $3 \mathrm{D}$ printers in the world and enhancement of tools and references for $3 \mathrm{D}$ modeling, all the users can print out their desired SenStick cases by themselves and attach our sensor to everything.

\section{Case Studies of SenStick}

SenStick, an ultra small sensor, can be embedded into various tiny things in our daily life. Our first target is our daily belongings such as glasses, chopsticks, and pens because sensorization of daily belongings is good to intuitively understand what can be sensed and which sensor is useful/effective. SenStick can upgrade normal glasses to intelligent ones which can monitor a head movement, posture, and the amount of sunlight received. If SenStick is embedded into chopsticks and pens, we can observe eating activities and handwriting activities, respectively. In the future, we will embed it into a stick for elderly monitoring, sports gears, musical instrument, 


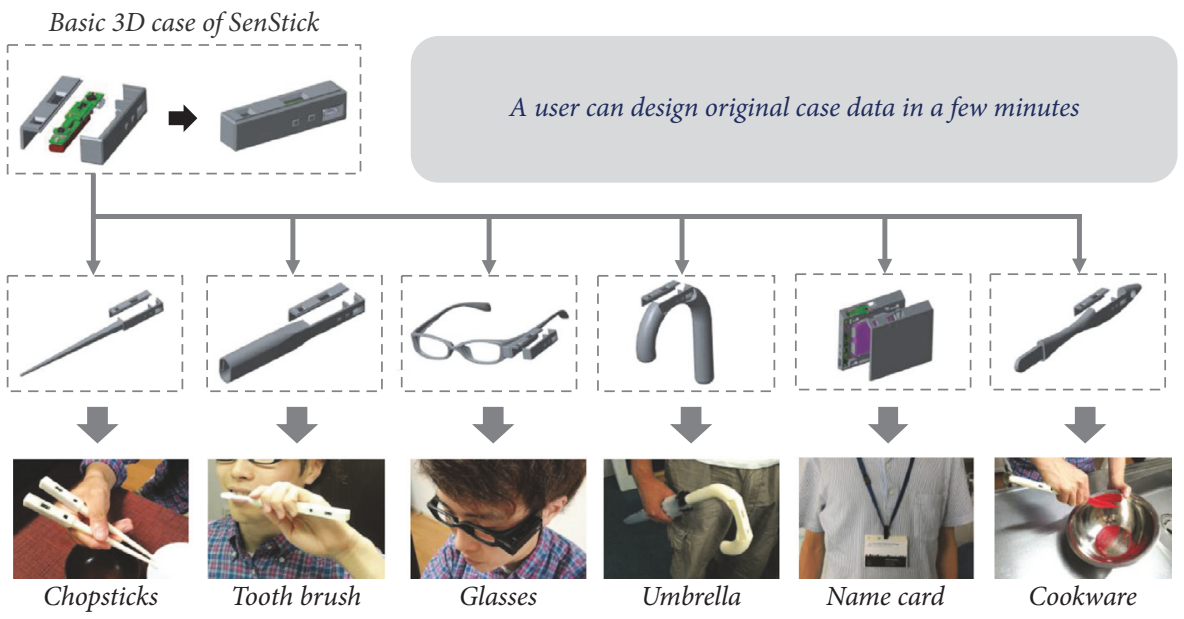

FIgURE 6: 3D case data of SenStick.

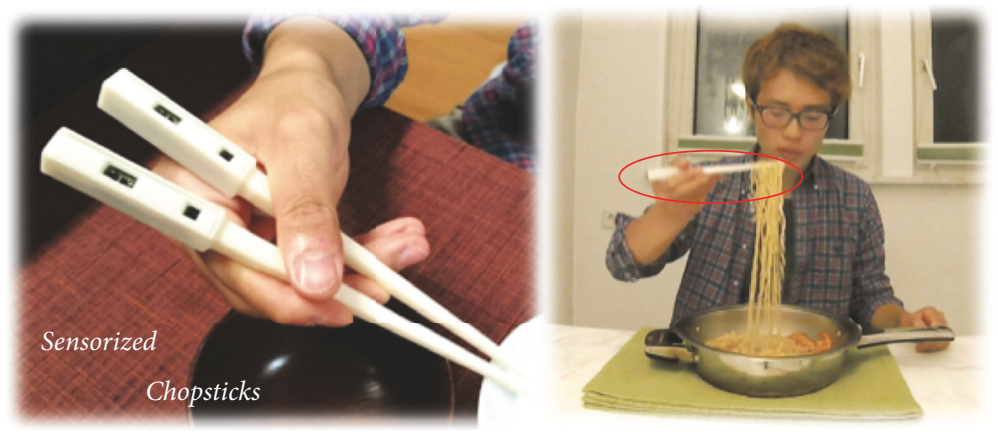

FIGURE 7: Eating activity recognition by sensorized chopsticks.

kitchen utensils, animals, stuffed toy, a remote control, and any kind of things that can be sensing targets. In this section, we introduce some case studies results utilizing SenStick.

4.1. Eating Behavior Recognition by Sensorized Chopsticks. In many cases, East Asian people eat meals with chopsticks. By analyzing the data obtained from chopsticks, there is a possibility that we can estimate the eating habits including answers for questions like "how did you eat?" and "what did you eat?" and so forth. These data are very useful for making healthcare applications and leading a healthy life. This is one reason why we develop the sensorized chopsticks using SenStick shown in Figure 7.

Research goals of the eating behavior recognition by sensorized chopsticks are as follows: G1 (behavior): recognizing the timing and speed and detecting "crop" and "intake" action; G2 (food type): classifying food content like rice, noodles, and so forth from the eating behavior; and G3 (person): identifying an individual from using chopsticks. In this paper, we show the research results on G1 and G2.

We conducted basic experiments to recognize the eating behavior (G1 and G2). We used acceleration and gyroscope data measured by SenStick, where the sensing rate is $10 \mathrm{~Hz}$. The purpose of experiment 1 is to understand the basic characteristics of sensing data from sensorized chopstick when a participant ate chips. The purpose of experiment 2 is to identify the food type from the difference in movement of chopsticks. We assumed 4 classes (C1: rice and dish, C2: miso soup, C3: noodles, and C4: shrimp) as food types.

Figure 8 shows time series of sensing data for a set of eating actions in experiment 1 . The eating actions are crop action and intake action. In crop action, 6-axis motion sensors detect movement (open and close) of the chopsticks. In intake action, sensors detect movement of the arm from the dish to the mouth. Each graph in Figure 8 shows certain correlation with both actions.

Figure 9 shows a typical signal for each food in experiment 2. In this experiment, we calculate the recognition accuracy of food type classification by using Random Forest classier of Weka. Tables 5 and 6 show the classification results. The average recognition accuracy was $89.6 \%$. If we did not have a SenStick, it would be hard to develop the sensorized chopsticks that can be used in the actual environment.

4.2. Daily Activity Monitoring by a Sensorized Belt. Recently, corpulent people are rapidly increasing, and about 700 million people belong to the obesity group [18]. Nowadays, many office workers use computers heavily and their sitting time 


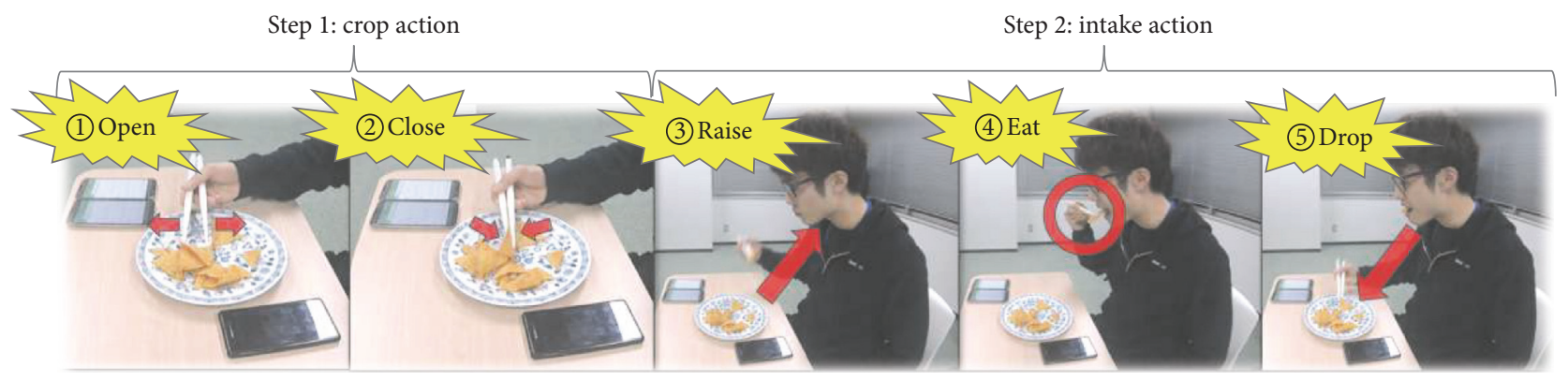

(1) (2) (3) (4) (5)

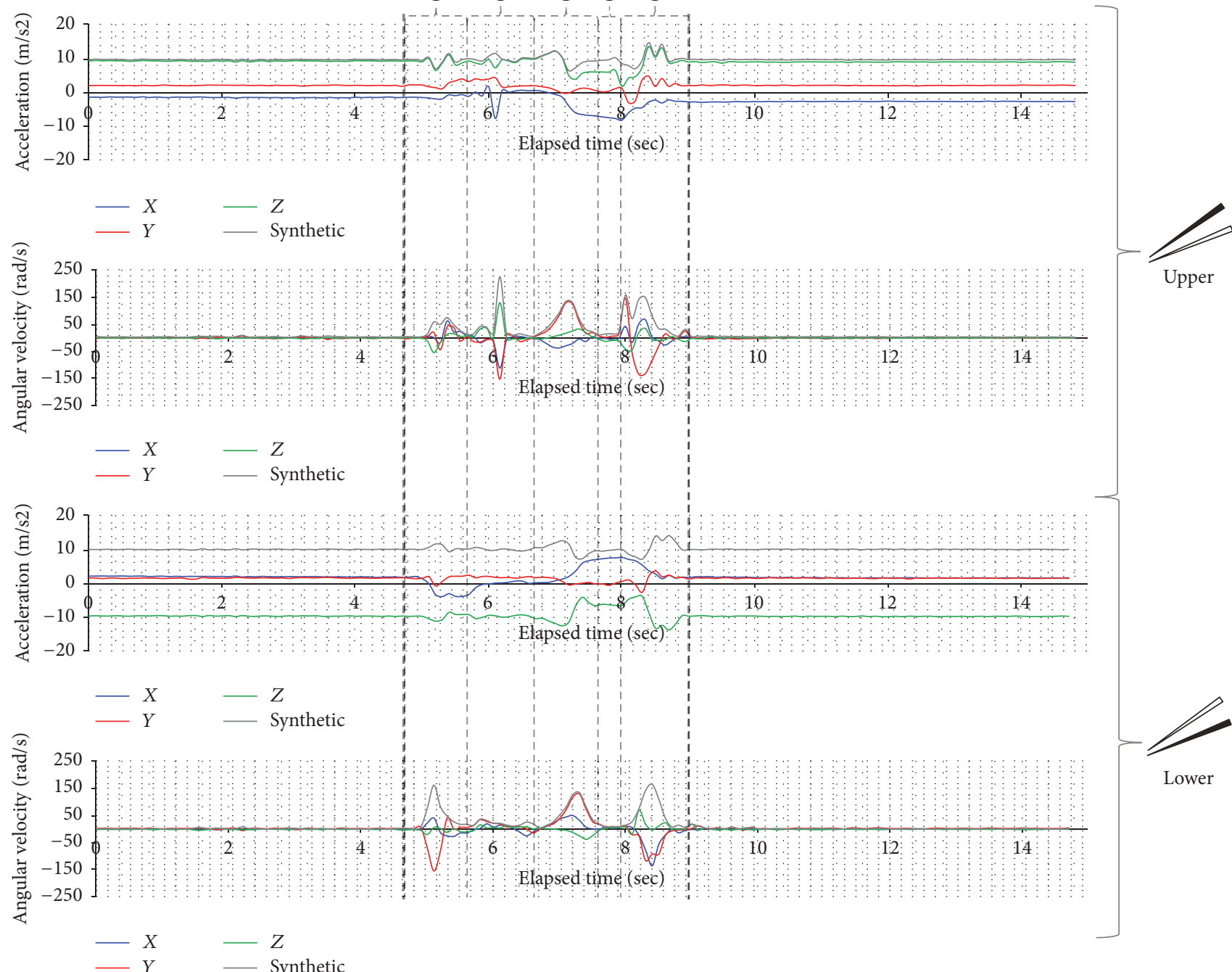

FIGURE 8: Time series of sensing data in eating activity.

in office increases. Keeping incorrect postures during long working time increases the risk of obesity of office workers. Therefore, it is necessary to monitor the daily activity of office workers for correcting the bad habits.

Motivated by this, we have developed a sensorized belt called Waiston Belt [8], which aims to monitor a user's daily activities for maintaining health. As products of belttype wearable devices, Welt [19] and Belty [20] are on sale. These provide the function of waist measurement, activity tracking, and step counting. However, API for obtaining sensing data is not provided, and it is not suitable for research purposes. Generally, it is hard for ordinary researchers to embed sensors, battery, BLE, and vibrator into a small bucklesize case that can be worn in everyday life. Nam et al. [21] have proposed a belt-attached device for monitoring posture. However, the device has not reached a sufficient level to be used on a daily basis because of exposed wiring and uncool appearance. However, by extending SenStick, we succeeded 


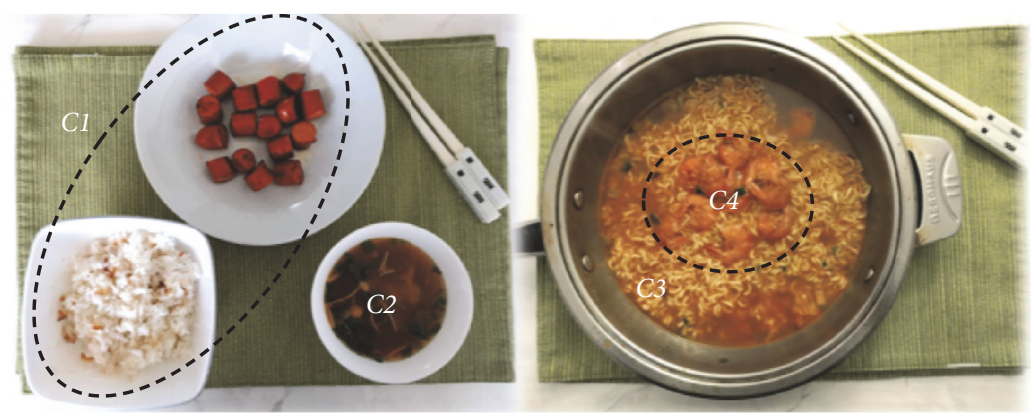

Typical signal of each food

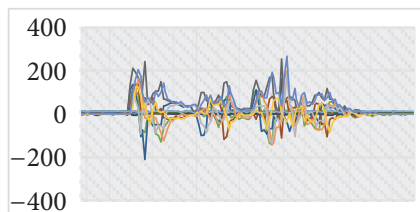

C1: rice \& dish

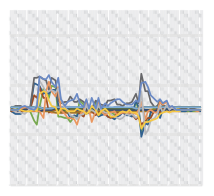

C2: miso soup

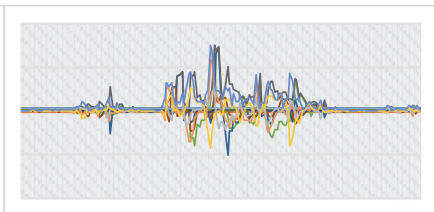

C3: noodles

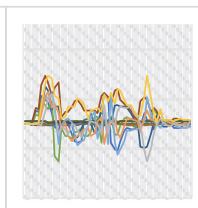

C4: shrimp

FIGURE 9: Eating activity recognition by sensorized chopsticks.
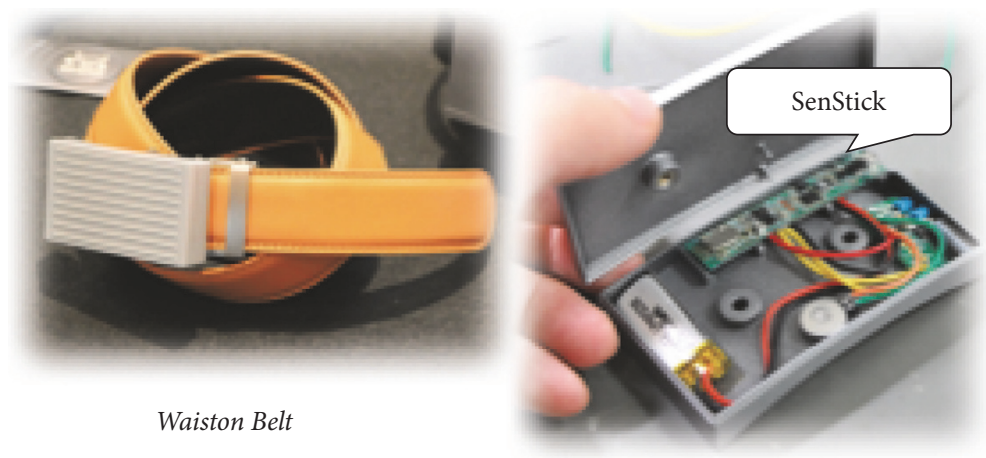

FIgUre 10: Waiston Belt based on SenStick.

TABLE 5: Experimental result (food type).

\begin{tabular}{lcccc}
\hline Food type & $\begin{array}{c}\text { Number of } \\
\text { pieces of data }\end{array}$ & Precision & Recall & F-Measure \\
\hline C1: rice and dish & 3011 & 0.894 & 0.945 & 0.919 \\
C2: miso soup & 2187 & 0.907 & 0.841 & 0.873 \\
C3: noodles & 2761 & 0.88 & 0.896 & 0.888 \\
C4: shrimp & 2091 & 0.907 & 0.88 & 0.893 \\
\hline
\end{tabular}

to develop a stylish prototype of Waiston Belt shown in Figure 10 quickly. Since the battery life of SenStick is 15 hours with a small battery ( $60 \mathrm{mAh})$, we can sense continuously in our daily lives. As shown in Figure 11, it is possible to estimate various users' contexts (How much did you walk? Are you using the stairs? Is posture good at work?) by analyzing time series of sensing data obtained from the sensorized belt.

An important point in this use case is that users' contexts can be estimated by combining multiple sensing data. For
TABLE 6: Confusion matrix of food type recognition.

\begin{tabular}{lcccc}
\hline & \multicolumn{4}{c}{ Predicted } \\
& C1 & C2 & C3 & C4 \\
\hline Actual & & & & \\
C1: rice and dish & 0.94 & 0.04 & 0.01 & 0.00 \\
C2: miso soup & 0.12 & 0.84 & 0.04 & 0.00 \\
C3: noodles & 0.02 & 0.02 & 0.90 & 0.06 \\
C4: shrimp & 0.01 & 0.01 & 0.11 & 0.88 \\
\hline
\end{tabular}

example, climbing stairs is estimated from the changes of acceleration and atmospheric pressure. The change of the humidity data will be helpful to detect that a user entered an air-conditioned room. A SenStick makes it possible to easily carry out research on behavior recognition with a combination of such multiple sensors.

We introduce basic experiments about the posture recognition during desk work by using this belt. The purpose of this experiment is to identify the posture type from the attitude 


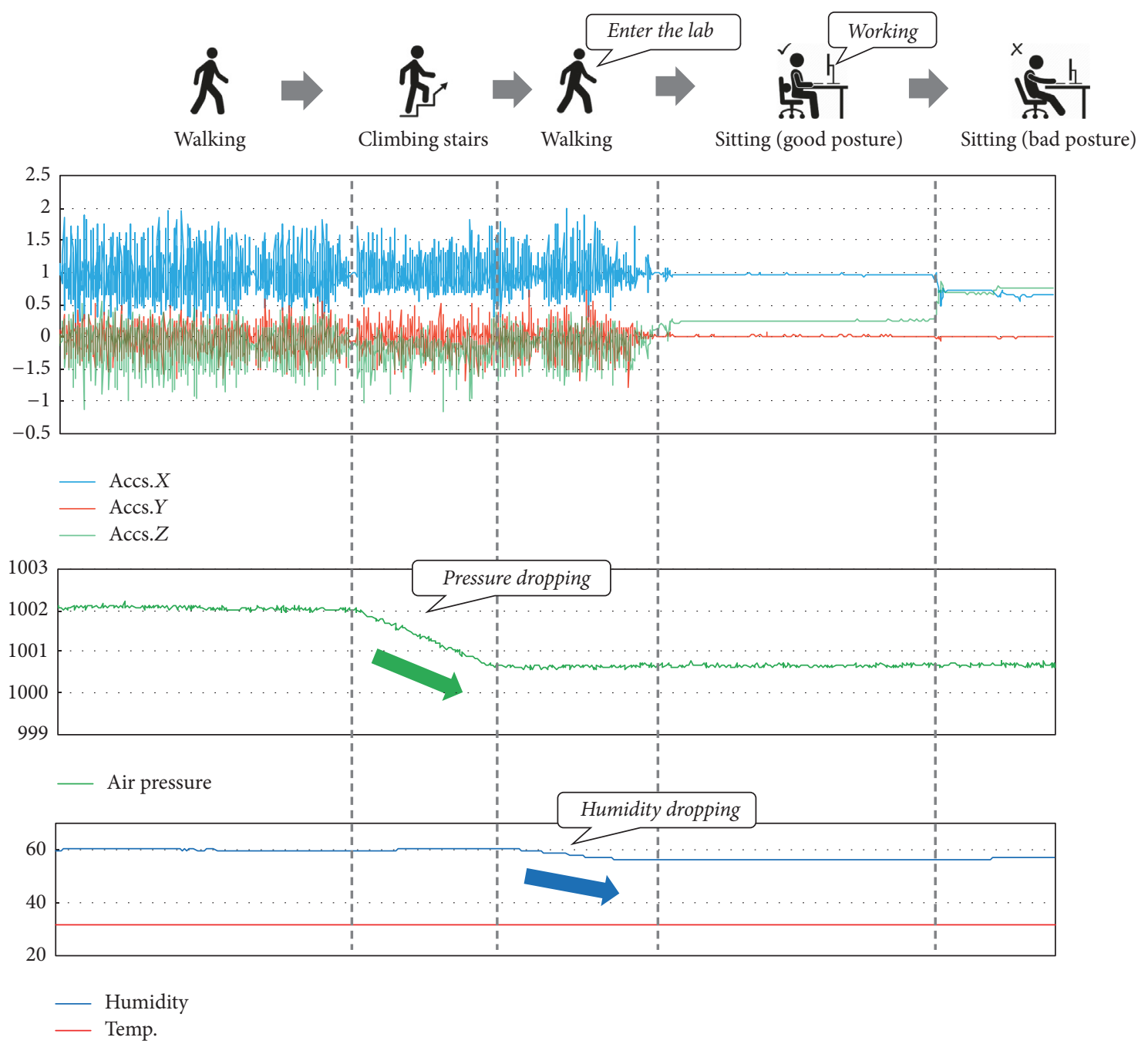

FIgURE 11: Time series of sensing data in daily activity.

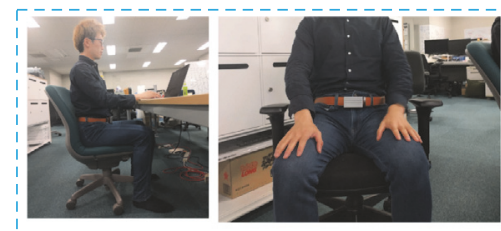

C1: good posture

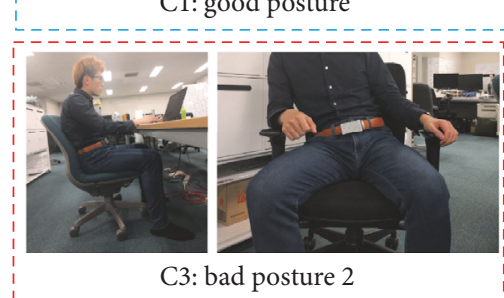

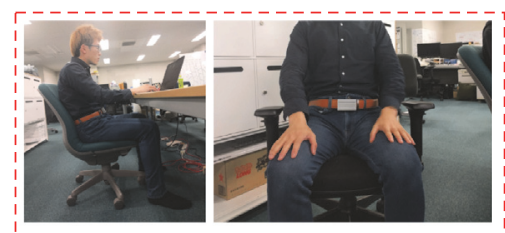

C2: bad posture 1

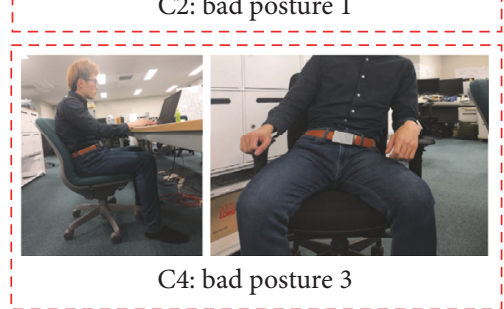

FIgURE 12: Time series of sensing data in posture monitoring.

angle of the belt calculated from 3 axial acceleration sensors. We set the sensing rate as $10 \mathrm{~Hz}$ and collected 6000 samples (10 min.) for each posture. We assumed 4 classes (C1: good posture, C2: bad posture 1, C3: bad posture 2, and C4: bad posture 3) as shown in Figure 12.
In this experiment, we calculated the recognition accuracy of posture type classification by using Random Forest classifier of Weka. Tables 7 and 8 show the classification results. The average recognition accuracy was $99.7 \%$. In the future, based on the result of posture estimation, we 


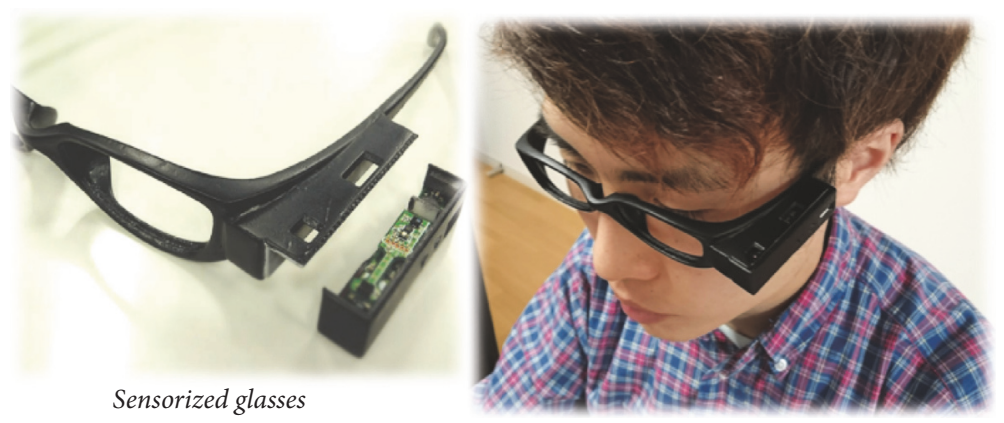

FIGURE 13: Sensorized glasses.

TABLE 7: Experimental result (posture type).

\begin{tabular}{lcccc}
\hline Posture type & $\begin{array}{c}\text { Number of } \\
\text { pieces of data }\end{array}$ & Precision & Recall & F-Measure \\
\hline C1: good posture & 6000 & 1.000 & 1.000 & 1.000 \\
C2: bad posture 1 & 6000 & 0.994 & 0.994 & 0.994 \\
C3: bad posture 2 & 6000 & 0.994 & 0.994 & 0.994 \\
C4: bad posture 3 & 6000 & 0.999 & 0.999 & 0.999 \\
\hline & & 0.997 & 0.997 & 0.997 \\
\hline
\end{tabular}

will develop a software application that suggests correcting his/her bad posture to a right posture during desk work.

4.3. Indoor Localization by Sensorized Glasses. We have proposed an indoor localization system using illuminance-based trilateration method [22]. In this system, we assume that the person wears glasses having an illuminance sensor as shown in Figure 13 and controllable light sources are deployed in the target environment. Our system controls lights and measures the variation of illuminance at the glasses. As shown in Figure 14 , the distances $(d 1-d 3)$ from each light $(l 1-l 3)$ to the user $(u)$ are estimated from the distance-illumination model constructed in advance, and user's position is estimated based on trilateration method using estimated distances.

As a result of an experiment where three controllable light sources were deployed in a room, we confirmed that our system could estimate the position within $0.5 \mathrm{~m}$ error on average. By using SenStick, we could easily develop the sensorized glasses equipped with illuminance sensor.

4.4. Sensorized Airsoft Gun. We have developed the sensorized airsoft gun for activity recognition in airsoft game as shown in Figure 15. Airsoft game is a sport in which participants eliminate opponents by hitting each other using replica weapons called airsoft guns. The graph of a typical signal from the sensorized airsoft gun is shown in Figure 16. A user can count the number of shots of a ball by attaching SenStick to his airsoft gun.

4.5. Another Example: Student's Unique Achievements and Survey Results. SenStick is also used in a lecture of IoT
TABLE 8: Confusion matrix of posture type recognition.

\begin{tabular}{lcccc}
\hline & \multicolumn{4}{c}{ Predicted } \\
& $\mathrm{C} 1$ & $\mathrm{C} 2$ & $\mathrm{C} 3$ & $\mathrm{C} 4$ \\
\hline Actual & & & & \\
C1: good posture & 1.000 & 0.000 & 0.000 & 0.000 \\
C2: bad posture 1 & 0.000 & 0.994 & 0.006 & 0.001 \\
C3: bad posture 2 & 0.000 & 0.006 & 0.994 & 0.000 \\
C4: bad posture 3 & 0.000 & 0.001 & 0.000 & 0.999 \\
\hline
\end{tabular}

prototyping. Students realize their unique IoT devices easily by using SenSticks. Here, we introduce some of the developed IoT devices and survey results about the usefulness of SenStick answered by students.

Figure 17 shows a sensorized pencil with two SenSticks. The sensorized pencil is developed to recognize the characters written by this pencil. Even though two SenSticks are embedded to detect precise movement of pencil, the size of the pencil is reasonable.

Figure 18 shows a sensorized name tag and digital signage. Since we changed the battery from $60 \mathrm{mAh}$ to $900 \mathrm{mAh}$, the tag keeps running more than one week. It aims to record employees' or students' daily activities to support their health. The digital signage informs the user who wears a sensorized name tag about the user's activity data when the user stands in front of it.

Figure 19 shows a sensorized spoon used in the digital fish catching game for children. In this game, the sensorized spoon detects the scooping movement of the hand. Thus, children can catch the digital fish displayed by the projection mapping by using sensorized spoon. This system was actually used at the university's open campus event, and around 100 children enjoyed this game and showed interest in IoT technology.

The survey results obtained from the ten graduate students (nine males and one female) who developed prototypes as mentioned above are shown in Table 9. A questionnaire is a five-grade form (5: strongly agree, 4: agree a little, 3: neither agree nor disagree, 2: disagree a little, and 1: strongly disagree). From the results of questions 1 and 2, many participants think that SenStick platform is useful for IoT 

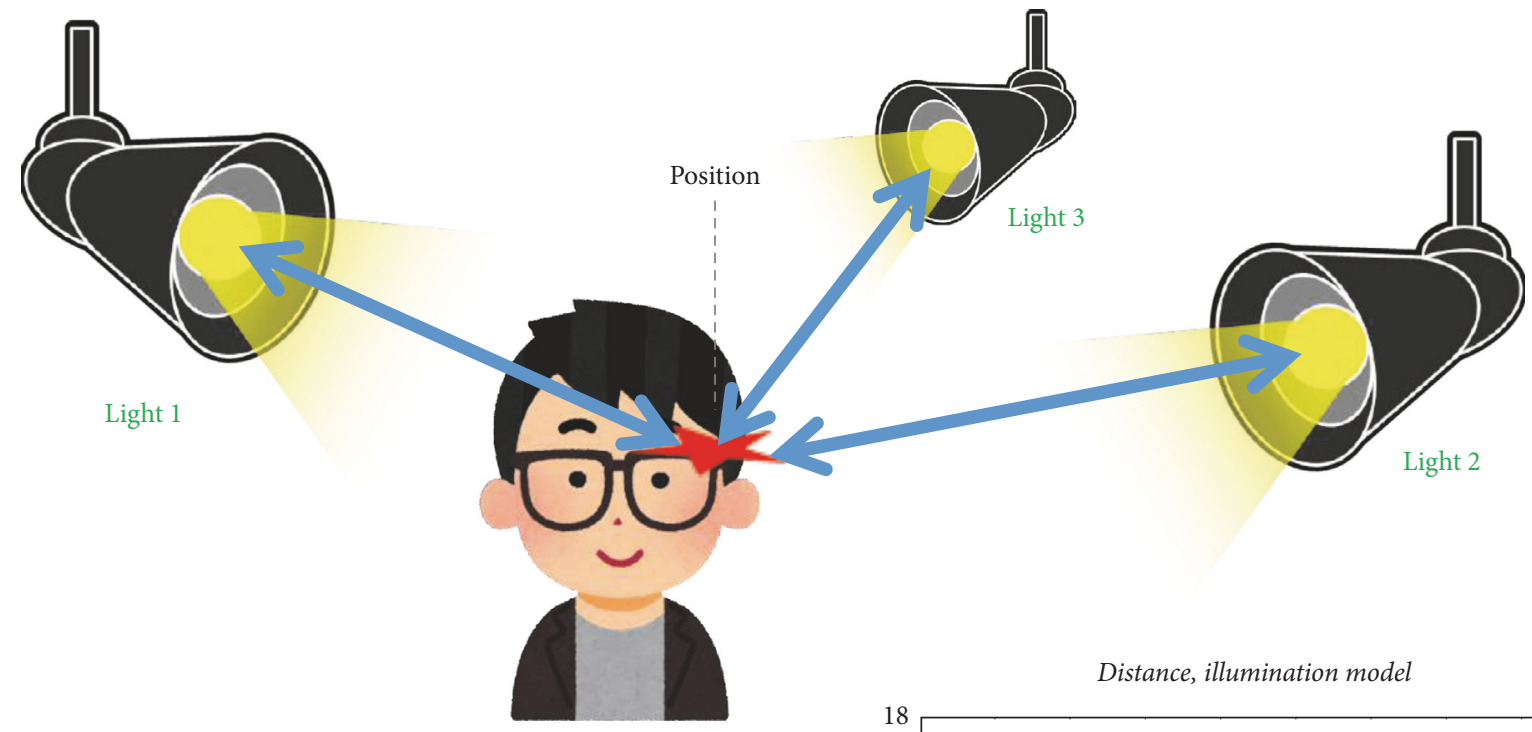

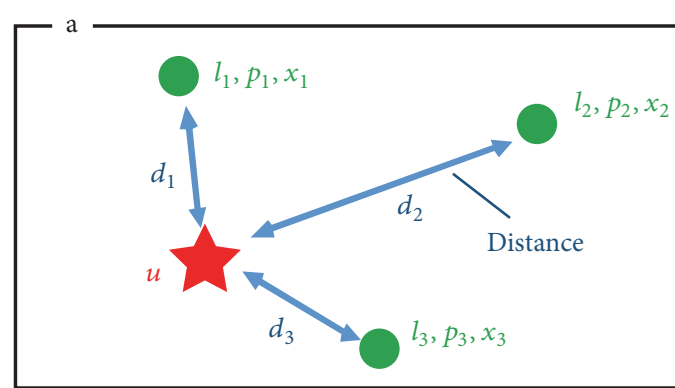

Using trilateration method
Distance, illumination model

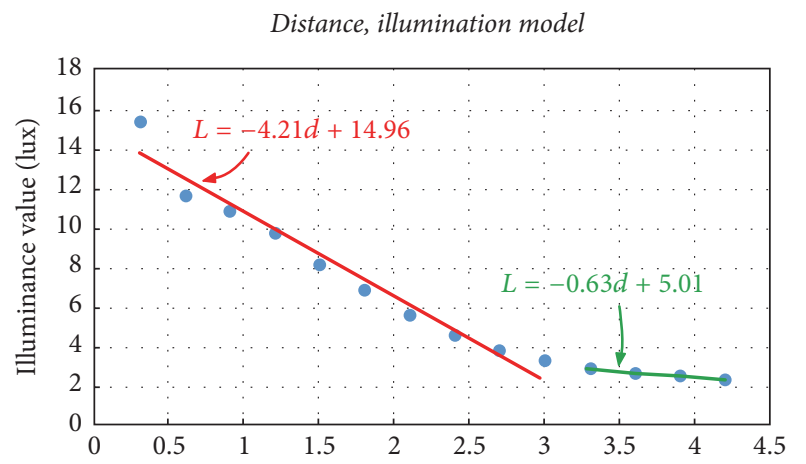

Distance between the illuminance sensor and the lighting device $(\mathrm{m})$

FIGURE 14: Indoor localization by sensorized glasses.

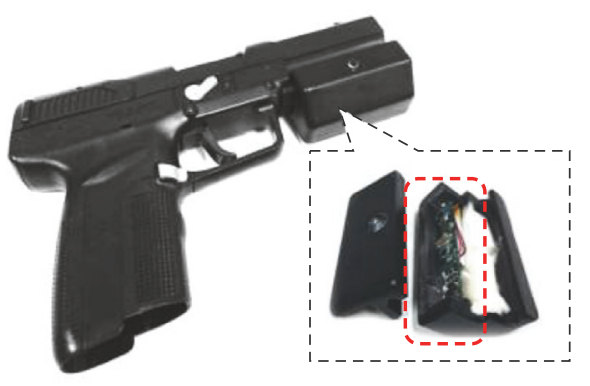

Sensorized airsoft gun

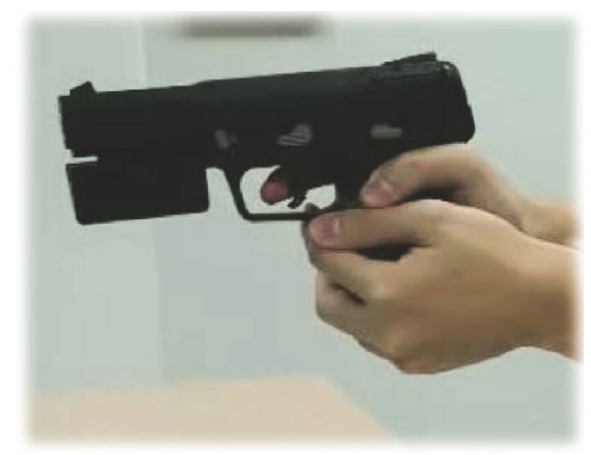

FIGURE 15: Sensorized airsoft gun. research and IoT education. Also the results of question 3 show that many students are interested in the SenStick and want to use it again. From the results of questions 4 and 5, we can see that usability and specification of SenStick are relatively high. There were opinions about the usefulness of SenStick platform such as "I could quickly try out ideas of IoT prototyping," "It was easy to collect sensing data," and "Since SenStick is small, it was easily attached to most of the things." On the other hand, there were opinions about improvements such as "I want to use higher sensing frequency $(50-100 \mathrm{~Hz})$," "I want to process a sensing data on SenStick," and "I want to modify the firmware itself depending on the application of the IoT device."

\section{Conclusion}

In this paper, we have introduced a smart and comprehensive sensing platform called SenStick, which is composed of 


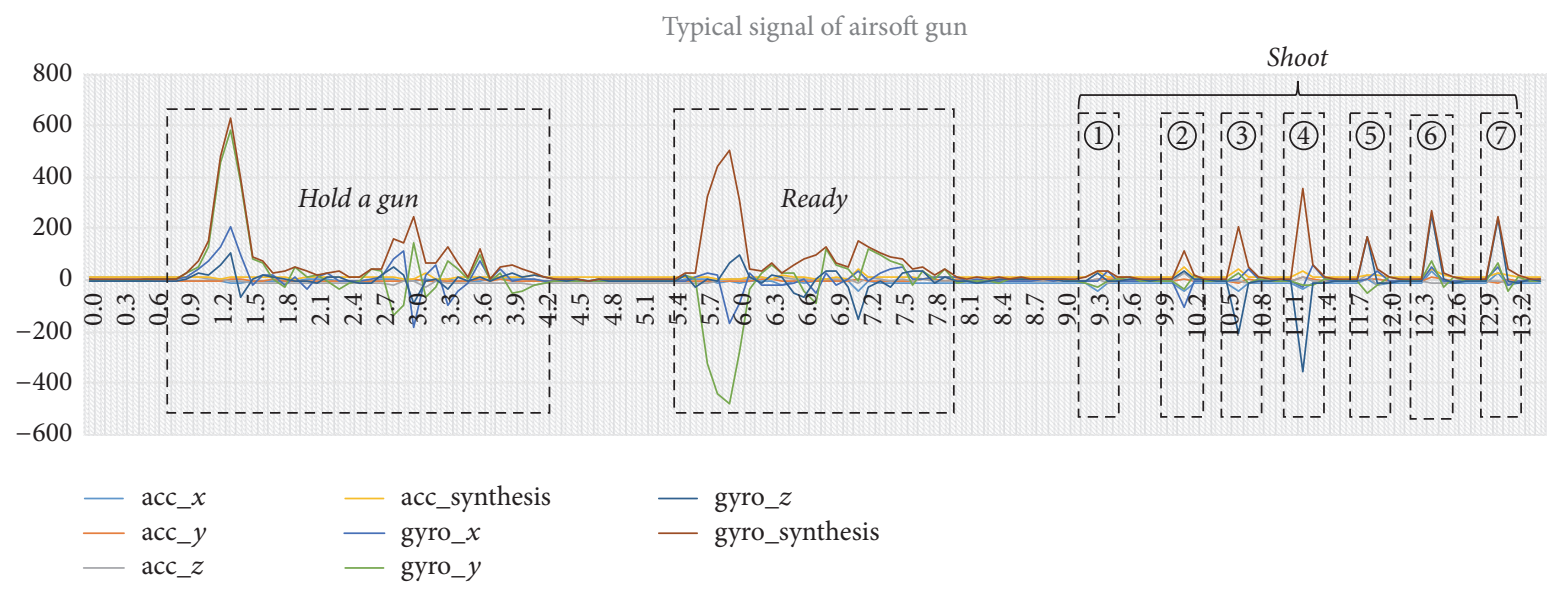

Figure 16: Time series of sensing data in shooting an airsoft gun.

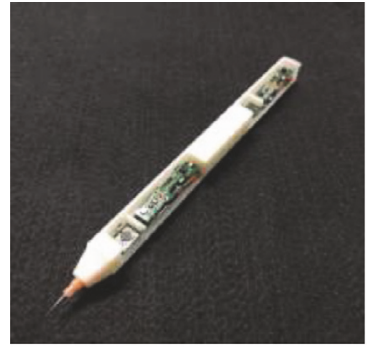

Sensorized pencil

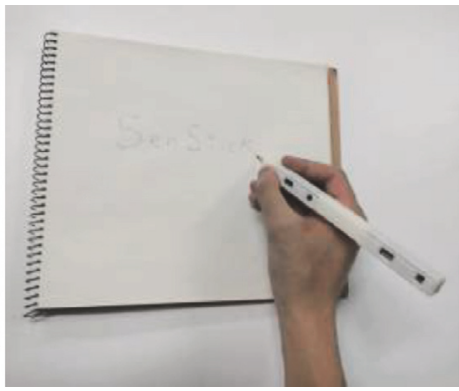

FIGURE 17: Sensorized pencil.

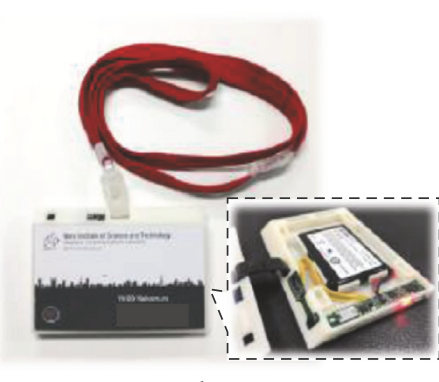

Sensorized name tag

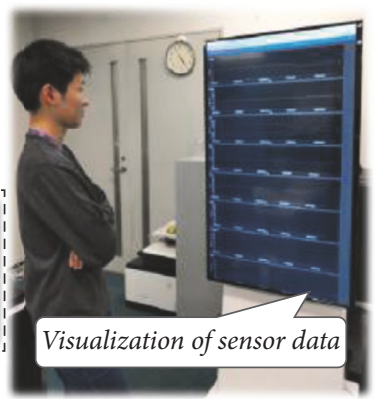

FIGURE 18: Sensorized name tag.

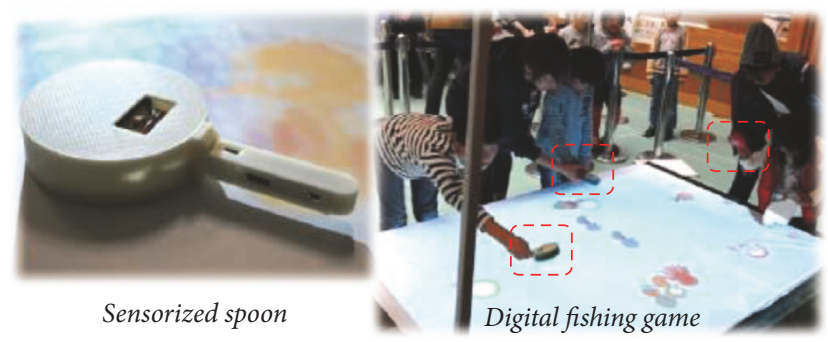

FIGURE 19: Sensorized spoon.
TABle 9: Questionnaire results about SenStick.

\begin{tabular}{lc}
\hline Question contents & Score \\
\hline $\begin{array}{l}\text { Q1. Do you think that SenStick will be useful for IoT } \\
\text { research? }\end{array}$ & 4.9 \\
$\begin{array}{l}\text { Q2. Do you think that SenStick will be useful for IoT } \\
\text { education? }\end{array}$ & 4.7 \\
Q3. Do you want to use SenStick again? & 4.9 \\
Q4. Do you think that SenStick was easy to use? & 4.1 \\
Q5. Are you satisfied with specification of SenStick? & 4.1 \\
\hline
\end{tabular}

hardware, software, and 3D case data. The main purpose of our platform is to simplify the sensorization of our personal belongings.

The hardware of SenStick is maybe one of the world's smallest sensor boards, which includes 8 kinds of sensors and BLE. In addition to the hardware, we also developed support software for managing, monitoring, recording, and viewing the hardware. By providing $3 \mathrm{D}$ case data, all the researchers can measure every tiny activity in daily life easily and efficiently. For an educational use, it is also useful for understanding sensors and prototyping the desired system including tiny censored things.

\section{Conflicts of Interest}

The authors declare that there are no conflicts of interest regarding the publication of this paper.

\section{Acknowledgments}

This work is supported in part by JST PRESTO and JSPS KAKENHI (Grant no. 17J10021) and "Research and Development of Innovative Network Technologies to Create the Future," the Commissioned Research of National Institute of Information and Communications Technology (NICT), Japan. 


\section{References}

[1] O. Brdiczka, M. Langet, J. Maisonnasse, and J. L. Crowley, "Detecting human behavior models from multimodal observation in a smart home," IEEE Transactions on Automation Science and Engineering, vol. 6, no. 4, pp. 588-597, 2009.

[2] J. Chen, A. Kam, J. Zhang, N. Liu, and L. Shue, "Bathroom activity monitoring based on sound," in Pervasive Computing: Third International Conference, PERVASIVE 2005, Munich, Germany, May 8-13, 2005. Proceedings, vol. 3468 of Lecture Notes in Computer Science, pp. 47-61, Springer, Berlin, Germany, 2002.

[3] G. Bauer, K. Stockinger, and P. Lukowicz, "Recognizing the UseMode of Kitchen Appliances from Their Current Consumption," in Smart Sensing and Context, vol. 5741 of Lecture Notes in Computer Science, pp. 163-176, Springer Berlin Heidelberg, Berlin, Heidelberg, 2009.

[4] K. Ouchi and M. Doi, "Indoor-outdoor activity recognition by a smartphone," in Proceedings of the the 2012 ACM Conference, p. 537, Pittsburgh, Pennsylvania, September 2012.

[5] A. Anjum and M. U. Ilyas, "Activity recognition using smartphone sensors," in Proceedings of the IEEE 10th Consumer Communications and Networking Conference (CCNC '13), pp. 914-919, IEEE, January 2013.

[6] Ó. D. Lara and M. A. Labrador, "A survey on human activity recognition using wearable sensors," IEEE Communications Surveys \& Tutorials, vol. 15, no. 3, pp. 1192-1209, 2013.

[7] “Jins meme", https://jins-meme.com/.

[8] Y. Matsuda, T. Ishioka, T. Hasegawa et al., "WaistonBelt: A belt for monitoring your real abdominal circumference forever," in Proceedings of the ACM International Joint Conference on Pervasive and Ubiquitous Computing and the 2015 ACM International Symposium on Wearable Computers, UbiComp and ISWC 2015, pp. 329-332, September 2015.

[9] M. Kurahashi, K. Murao, T. Terada, and M. Tsukamoto, "Personal identification system based on rotation of toilet paper rolls," in Proceedings of the IEEE International Conference on Pervasive Computing and Communications Workshops (PerCom Workshops '17), pp. 521-526, IEEE, Kona, Hawaii, USA, March 2017.

[10] "Hapifork," https://www.hapi.com/.

[11] Y. Arakawa, "SenStick: Sensorize every things," in Proceedings of the ACM International Joint Conference on Pervasive and Ubiquitous Computing and the 2015 ACM International Symposium on Wearable Computers, UbiComp and ISWC 2015, pp. 349-352, September 2015.

[12] Y. Nakamura, T. Kanehira, Y. Arakawa, and K. Yasumoto, "SenStick 2: Ultra tiny all-in-one sensor with wireless charging," in Proceedings of the 2016 ACM International Joint Conference on Pervasive and Ubiquitous Computing, UbiComp 2016, pp. 337340, September 2016.

[13] “Sensortag cc2541 (texas instruments)," http://www.ti.com/tool/ cc2541dk-sensor.

[14] "Iot smart module," http://www.alps.com/j/iotsmart/.

[15] “Tsnd121 (atr-promotions)," http://www.atr-p.com/products/ TSND121.html.

[16] “Wax9 (axivity)," http://axivity.com/product/wax9.

[17] Uk. biobank, "Uk biobank," http://www.ukbiobank.ac.uk/.

[18] J. C. Seidell and J. Halberstadt, "The global burden of obesity and the challenges of prevention," Annals of Nutrition and Metabolism, vol. 66, supplement 2, pp. 7-12, 2015.
[19] "Welt: The smart belt for fashion and health," https://www.weltcorp.com/.

[20] "Belty power: The belt your really deserve," https://www.belty .co/.

[21] H. Nam, J.-H. Kim, and J.-I. Kim, "Smart Belt : A wearable device for managing abdominal obesity," in Proceedings of the International Conference on Big Data and Smart Computing, BigComp 2016, pp. 430-434, January 2016.

[22] K. Moriya, M. Fujimoto, Y. Arakawa, and K. Yasumoto, "Indoor localization based on distance-illuminance model and active control of lighting devices," in Proceedings of the 2016 International Conference on Indoor Positioning and Indoor Navigation, IPIN 2016, pp. 1-6, October 2016. 


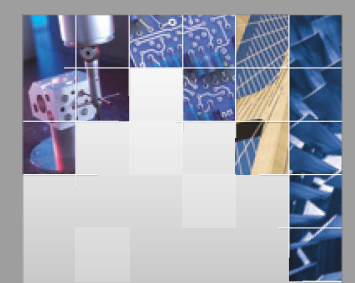

\section{Enfincering}
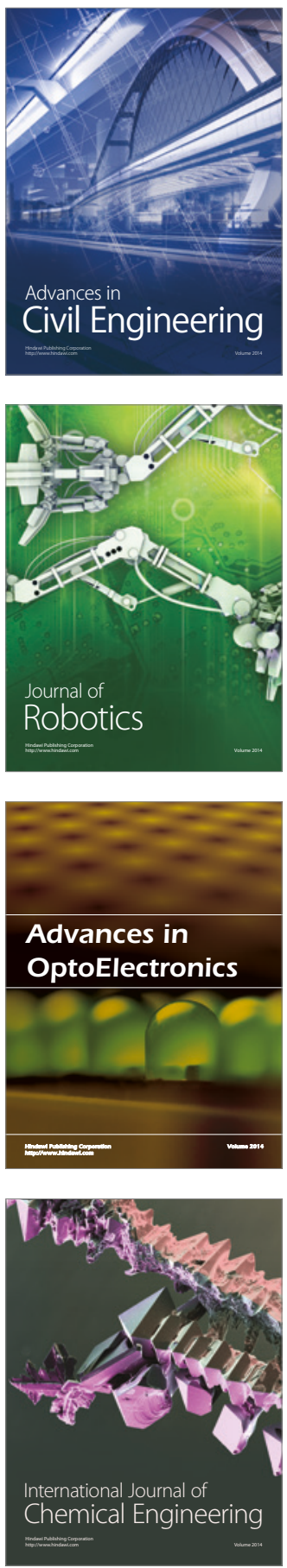

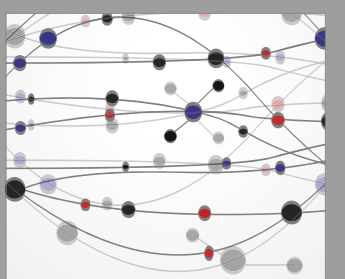

The Scientific World Journal

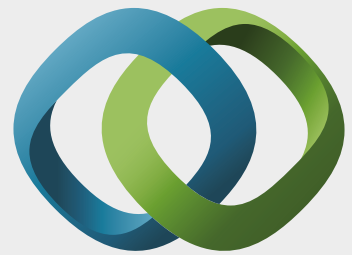

\section{Hindawi}

Submit your manuscripts at

https://www.hindawi.com
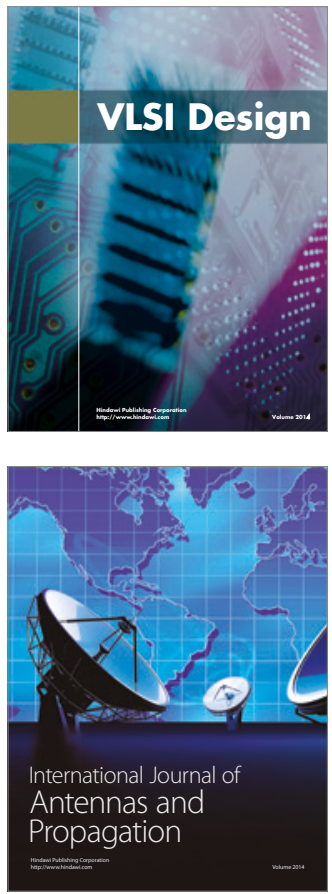

\section{Rotating}

Machinery
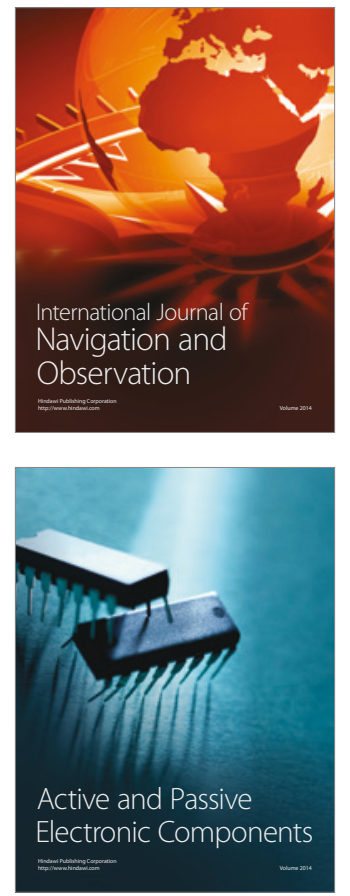
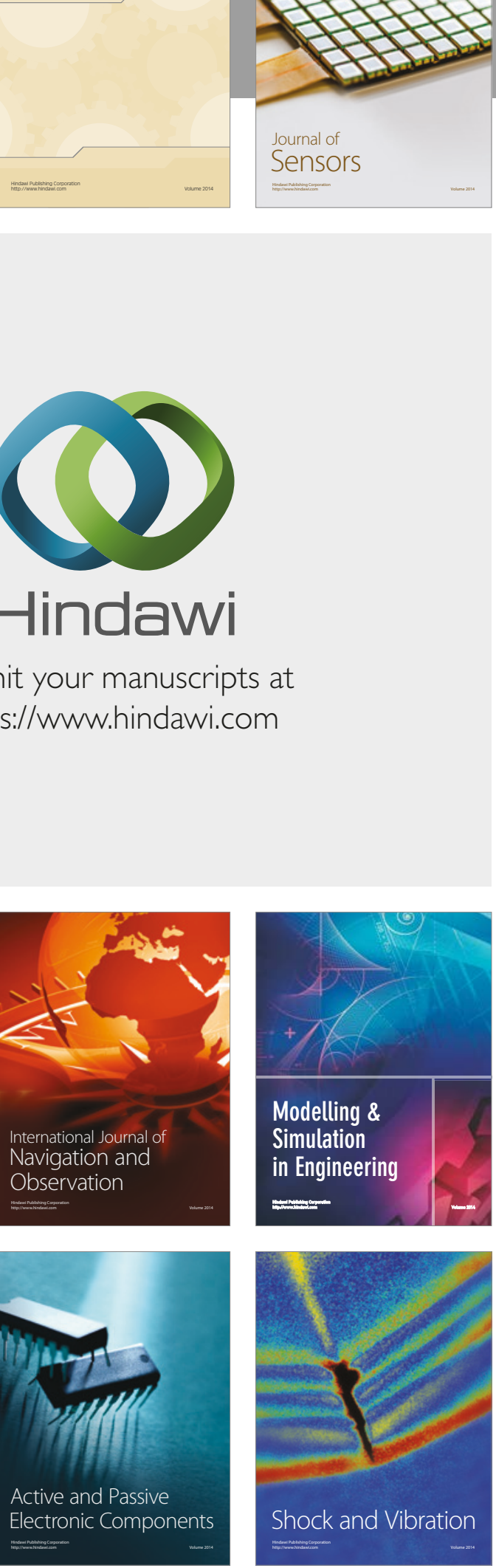
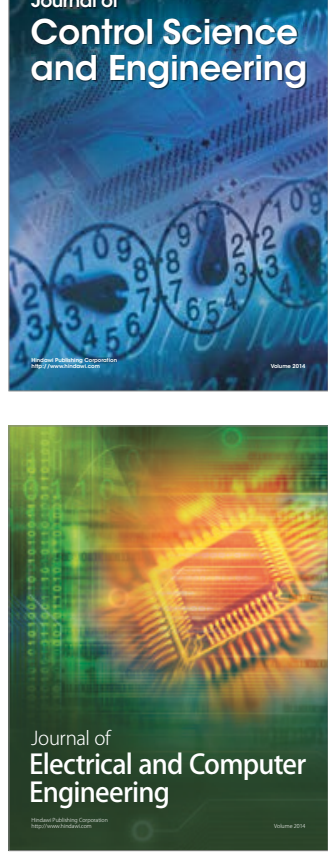

Distributed

Journal of

Control Science

and Engineering
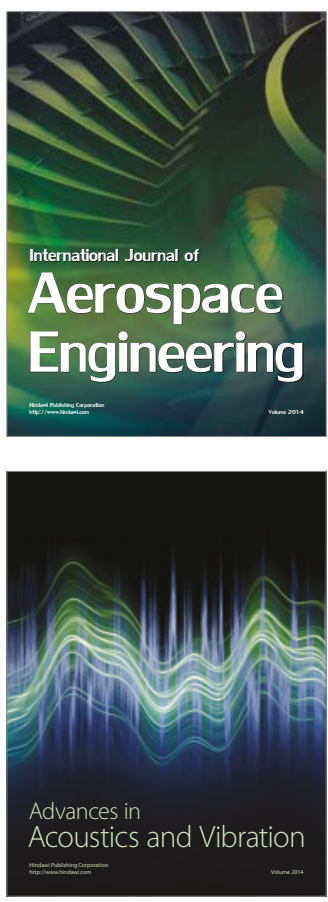

Sensor Networks 